\title{
Desempenho e rendimento de carcaça em frangos de corte de um a 46 dias alimentados com dietas contendo diferentes níveis de valina e reduzido teor proteico
}

\author{
[Performance and carcass yield of broilers from 1 to 46 days fed diets containing different \\ levels of valine and reduced protein content] \\ V.C. Caetano ${ }^{1}$, D.E. Faria ${ }^{2}$, A.R.M. Caniatto ${ }^{1}$, D.E. Faria Filho ${ }^{2}$,V.S. Nakagi ${ }^{2}$ \\ ${ }^{1}$ Aluno de pós-graduação - FZEA-USP -Pirassununga - SP \\ ${ }^{2}$ FZEA-USP - Pirassununga - SP \\ RESUMO
}

\begin{abstract}
Este estudo teve como objetivo avaliar as relações de valina:lisina digestíveis em dietas com teor reduzido de proteína bruta (PB) e os efeitos dessa redução sobre desempenho e rendimento de carcaça em frangos de corte. Foram utilizados 1200 pintos machos seguindo modelo inteiramente ao acaso, com seis tratamentos de seis repetições (exceto controle, com 10 repetições), compostos por 30 aves cada. O tratamento controle (T1) foi formulado conforme os níveis de proteína bruta e aminoácidos (AAs) recomendados por Rostagno et al. (2011), e os demais tratamentos (T2 a T6) tiveram seus níveis de PB reduzidos (4\% em relação ao controle) e variaram em função da relação valina:lisina digestíveis, com cinco níveis equidistantes em intervalos de 0,07:1, variando de 0,63:1 e 0,91:1 (dietas até 21 dias) e de 0,64:1 e 0,92:1 (dietas após 21 dias). As seguintes características de desempenho foram avaliadas: ganho de peso, consumo de ração, conversão alimentar, viabilidade criatória e índice de eficiência produtiva. Aos 46 dias de idade, seis animais por repetição foram abatidos para determinação de rendimento de carcaça e de cortes comerciais. As diferentes relações valina:lisina digestíveis não influenciaram o desempenho dos animais $(\mathrm{P}>0,05)$ para nenhuma característica avaliada. A redução proteica piorou a conversão alimentar dos animais $(\mathrm{P} \leq 0,05)$ até os 21 dias. Os resultados sugerem que os níveis de valina utilizados não afetam o desempenho dos animais, apenas o rendimento de peito e que, portanto, a redução proteica não é recomendada durante as três primeiras semanas de criação.
\end{abstract}

Palavras-chave: aminoácido, exigência, proteína ideal, rendimento de peito

\begin{abstract}
This study aimed to evaluate valine:lysine ratios in diets with reduced content of crude protein and the effects of this reduction on the performance of broiler chickens. 1200 male chicks were used following a complete randomized design with six replicates of six treatments (except control, with 10 replicates), each one with 30 chicks. The control treatment (T1) was formulated following levels of crude protein $(C P)$ and the amino acids (AAs) recommended by Rostagno et al. (2011), and the other treatments (T2 to T6) had reduced levels of CP (4\% compared to control) and varied in proportion valine:lysine, with 5 levels at equidistant intervals 0.07:1 ranging from 0.63:1 to 0.91:1 (up to 21 days) and from 0.64:1 to 0.92:1 (after 21 days). The performance characteristics measured were: weight gain, feed intake, feed conversion, viability and productive efficiency index. At 46 days six animals per replicate were slaughtered for evaluation of carcass and commercial cuts. The different valine:lysine ratios did not affect animal performance $(P>0.05)$. Reducing protein impaired feed conversion $(P \leq .05)$ up to 21 days. The results suggest that levels of valine used did not affect the broilers' performance, however, breast meat yield and reduced protein are not recommended during the first three weeks.
\end{abstract}

Keywords: aminoacids, breast yield, ideal protein, requirement

Recebido em 10 de abril de 2014

Aceito em 27 de março de 2015

E-mail: vinicius.caetano@usp.br 


\section{INTRODUÇÃO}

A avicultura apresentou, nas últimas décadas, avanços extraordinários em genética, sanidade, manejo e nutrição, que lhe renderam posição de destaque no agronegócio brasileiro e no mundial. Tendo em vista que a alimentação representa aproximadamente $70 \%$ dos custos totais de produção avícola e possui papel fundamental no desempenho dos animais, estudos que buscam nutrição de baixo custo com o melhor desempenho animal são de enorme importância para o contínuo desenvolvimento do setor.

Por ser a proteína um dos componentes mais caros nas dietas das aves (Cancherini et al., 2005), uma formulação que ofereça um balanço exato dos aminoácidos (AAs), sem excesso ou deficiência, pode reduzir o nível de proteína bruta (PB) na formulação da dieta e resultar numa possível redução de custo (Hisano e Portz, 2007). A formulação de dietas com esse conceito, chamado de proteína ideal, só foi possível após o início da produção de aminoácidos industriais, quando se conseguiu incluir níveis mais próximos às exigências dos animais.

A metionina, a lisina e a treonina, os três primeiros AAs limitantes para frangos de corte, assim como o triptofano, já são amplamente utilizadas com sucesso na formulação das dietas. Segundo Corzo et al. (2009), a valina vem sendo apontada como o quarto aminoácido (AA) limitante em dietas para frangos de corte à base de milho e farelo de soja, sobretudo devido à sua baixa concentração em alimentos de origem vegetal e sua grande importância no empenamento, no sistema imune, no ganho de peso e na conversão alimentar.

Com a suplementação de aminoácidos industriais, consegue-se diminuir os teores de PB e, consequentemente, reduzir custos de formulação, principalmente com a menor inclusão de farelo de soja. Até a suplementação do terceiro aminoácido essencial (treonina), grandes avanços foram feitos na nutrição de frangos de corte no que diz respeito à redução proteica. Porém, para o quarto AA essencial, mais estudos precisam ser realizados, pois a redução mais severa de $\mathrm{PB}$ normalmente causa perdas de desempenho e de rendimento de carcaça.

Estudos que visam avaliar e/ou atualizar as exigências tanto de proteína quanto de aminoácidos em frangos de corte tornam-se imprescindíveis para que a nutrição continue acompanhando e reforçando os recentes avanços da avicultura.

O objetivo deste trabalho foi avaliar o melhor nível de valina em dietas com teor reduzido de PB e verificar o efeito dessa redução proteica sobre o desempenho e o rendimento de carcaça em frangos de corte até 46 dias..

\section{MATERIAL E MÉTODOS}

Foram utilizados 1200 pintos machos de um dia de idade, da linhagem comercial Cobb 500®, com peso inicial de 46,22 $\pm 0,51 \mathrm{~g}$. Os animais foram alojados seguindo-se o modelo inteiramente ao acaso, com seis tratamentos e seis repetições, à exceção do tratamento controle, com 10 repetições, o que totalizou 40 parcelas experimentais de 30 aves cada. Os frangos permaneceram em experimento por 46 dias.

Os tratamentos variaram em função da PB e dos níveis de relação valina:lisina (Tab. 1), sendo: T1 - tratamento controle com níveis nutricionais recomendados por Rostagno et al. (2011); T2 ao T6 - tratamentos com 4\% de redução na PB com diferentes níveis de relações valina:lisina digestíveis:

- T2: dois níveis abaixo do recomendado $(-0,14)$ da relação valina:lisina digestível $(0,63: 1$ até 21 dias, e 0,64:1 após 21 dias);

- T3: um nível abaixo do recomendado $(-0,07)$ da relação valina:lisina digestível $(0,70: 1$ até 21 dias, e 0,71:1 após 21 dias);

- T4: nível recomendado da relação valina:lisina digestível (0,77:1 até 21 dias, e 0,78:1 após 21 dias);

- T5: um nível acima do recomendado $(+0,07)$ da relação valina:lisina digestível $(0,84: 1$ até 21 dias, e 0,85:1 após 21 dias);

- T6: dois níveis acima do recomendado $(+0,14)$ da relação valina:lisina digestível $(0,91: 1$ até 21 dias, e 0,92:1 após 21 dias). 
Tabela 1. Indicação dos tratamentos experimentais

\begin{tabular}{cccc}
\hline Tratamentos & Valina:lisina $^{1}$ & Valina:lisina $^{2}$ & Proteína bruta $^{3}$ \\
\hline 1 & $0.77: 1$ & $0.78: 1$ & $100 \%$ \\
3 & $0.63: 1$ & $0.64: 1$ & $96 \%$ \\
4 & $0.70: 1$ & $0.71: 1$ & $96 \%$ \\
5 & $0.77: 1$ & $0.78: 1$ & $96 \%$ \\
6 & $0.84: 1$ & $0.85: 1$ & $96 \%$ \\
\hline
\end{tabular}

${ }^{1}$ Relação valina:lisina nas dietas até 21 dias. ${ }^{2}$ Relação valina:lisina nas dietas após 21 dias. ${ }^{3}$ Valores de proteína bruta em relação ao recomendado por Rostagno et al. (2011).

Os níveis dos demais nutrientes e da energia metabolizável foram calculados seguindo recomendação de Rostagno et al. (2011). Os aminoácidos lisina, metionina+cistina, treonina, triptofano, arginina e isoleucina foram suplementados às dietas em sua forma industrial em quantidades que, no mínimo, atendessem as recomendações sugeridas por Rostagno et al. (2011)

Para a formulação, realizaram-se as análises de umidade, proteína bruta, aminoácidos totais e aminoácidos digestíveis dos principais alimentos em termos de composição das rações (milho e farelo de soja) via HPLC (High-performance liquid chromatography), no LABTEC Laboratório de Análises Químicas Ltda. A composição dos demais nutrientes do milho e da soja, além dos demais ingredientes, foi estabelecida de acordo com as tabelas de composição química e os valores energéticos dos alimentos para aves e suínos de Rostagno et al. (2011).

Os níveis de PB e aminoácidos totais foram analisados pelo Laboratório da Ajinomoto Animal Nutrition ${ }^{\circledR}$, via HPLC (Highperformance liquid chromatography). A PB também foi analisada no Laboratório de Avicultura da Faculdade de Zootecnia e Engenharia de Alimentos USP-Pirassununga, pela metodologia da AOAC (1996).

As aves foram alojadas com um dia de idade, no aviário experimental com dimensões de 6 × 32 metros, com duas salas de 20 boxes cada, previamente limpo e desinfetado. O alojamento foi realizado sobre cama de maravalha reutilizada, em boxes experimentais de $2,47 \mathrm{~m}^{2}$ cada. O programa de luz adotado foi de $23 \mathrm{~h}$ de luz e uma hora de escuro durante todo o experimento. Ração e água foram fornecidas à vontade durante todo o período experimental.
Foram avaliados o ganho de peso (GP), o consumo de ração (CR), a conversão alimentar (CA) e a viabilidade criatória (VC) para o período inicial (um a 21 dias), e o índice de eficiência produtiva (IEP), além dos anteriores, para o período total (um a 46 dias de idade). O IEP foi determinado pela fórmula: (ganho de peso diário $(\mathrm{g}) \times$ viabilidade)/CA x 10, em que a viabilidade foi obtida por meio das mortalidades registradas durante todo o período experimental.

As carcaças evisceradas, sem cabeça, pés e pescoço, foram resfriadas por aproximadamente seis horas; após esse período, foram obtidos os cortes comercias de asa, coxa, sobrecoxa e peito sem pele e osso. A carcaça eviscerada e os cortes comerciais foram, então, pesados em balança digital de precisão $(0,01 \mathrm{~g})$.

O rendimento de carcaça foi expresso em relação ao peso corporal da ave no momento do abate [(peso carcaça x 100/peso vivo)], e o rendimento das partes em função do peso da carcaça eviscerada, sem penas, pés, cabeça e pescoço [(peso da parte x 100/peso carcaça)], conforme Mendes et al. (2004).

Os dados obtidos foram submetidos às análises de variância, e as médias comparadas pelo teste de Tukey e/ou contrastes das médias, ao nível de $5 \%$ de probabilidade, utilizando-se o programa estatístico SAS® (2002).

A metodologia empregada neste experimento foi aprovada pelo Comitê de Ética em Pesquisa da FZEA-USP, sob protocolo $\mathrm{n}^{\circ}$. 13.1.2248.74.8.

\section{RESULTADOS E DISCUSSÃO}

Os resultados das características de desempenho de frangos de corte machos de um a sete dias e de um a 21 dias encontram-se na Tab. 2. Durante a fase pré-inicial (um a sete dias), não foram 
verificadas diferenças significativas $(P>0,05)$ entre as médias para nenhuma variável. Já no período de um a 21 dias, o contraste entre as médias de CA do tratamento controle e os demais tratamentos foi significativo $(\mathrm{P}<0,05)$, sendo pior nas dietas com teor proteico reduzido.

Costa et al. (2001), ao trabalharem com níveis de $\mathrm{PB}$, encontraram efeito quadrático $(\mathrm{P}<0,01)$ para $\mathrm{CA}$ em frangos de corte macho na fase inicial, com estimativa de nível ótimo de $22,42 \%$ de PB para essa variável. Além disso, os mesmos autores relatam efeito linear sobre o consumo de ração $(\mathrm{P}<0,05)$ pelos frangos de corte machos, sem que houvesse efeito significativo para ganho de peso $(\mathrm{P}>0,05)$. Em referido estudo, os autores utilizaram apenas a suplementação de metionina, lisina e treonina, o que pode justificar exigência de proteína maior que em dietas suplementadas com maior número de aminoácidos.
Rostagno et al. (2002) observaram piora no desempenho de frangos de corte submetidos a dietas com $18 \%$ de PB de 08 a 21 dias de idade, contudo, com $19 \%$ de $\mathrm{PB}$, o desempenho foi semelhante ao grupo controle quando suplementado com glicina. Em trabalho que utilizou frangos de corte de um a 21 dias, Silva $e t$ al. (2006) encontraram resultados de desempenho semelhantes quando se comparou a dieta controle $(21,4 \%$ de PB suplementada com lisina e metionina industrial) com as dietas contendo 19\% de PB (adição dos AAs anteriores e valina industrial) e $17 \%$ de PB (adição dos AA anteriores e arginina, treonina e isoleucina). Porém, ao nível de $15 \%$ de PB (adição dos AA anteriores, triptofano e fenilalanina industrial), houve piora no consumo de ração e ganho de peso.

Tabela 2. Médias de ganho de peso (GP), consumo de ração (CR), conversão alimentar (CA) e viabilidade criatória (VC) de frangos de corte nas fases pré-inicial e inicial

\begin{tabular}{|c|c|c|c|c|}
\hline \multicolumn{5}{|c|}{ 1-7 dias } \\
\hline Relação (val:lis) & GP (g/ave) & CR (g/ave) & $\mathrm{CA}$ & $\mathrm{VC}(\%)$ \\
\hline Controle & 137,57 & 140,17 & 1,020 & 100,00 \\
\hline $0,63: 1$ & 135,66 & 143,33 & 1,058 & 100,00 \\
\hline $0,70: 1$ & 137,76 & 143,19 & 1,049 & 99,45 \\
\hline $0,77: 1$ & 139,82 & 145,88 & 1,044 & 100,00 \\
\hline $0,84: 1$ & 137,51 & 142,79 & 1,040 & 100,00 \\
\hline $0,91: 1$ & 135,75 & 142,22 & 1,049 & 100,00 \\
\hline \multicolumn{5}{|c|}{ ANOVA - contraste - regressão } \\
\hline ANOVA & ns & $\mathrm{ns}$ & $\mathrm{ns}$ & ns \\
\hline $\mathrm{CV}(\%)^{1}$ & 6,07 & 4,75 & 2,34 & 0,52 \\
\hline \multicolumn{5}{|c|}{$1-21$ dias } \\
\hline Relação (val:lis) & GP (g/ave) & CR (g/ave) & $\mathrm{CA}$ & $\mathrm{VC}(\%)$ \\
\hline Controle & 984,75 & 1311,58 & $1,333 \mathrm{a}$ & 98,66 \\
\hline $0,63: 1$ & 954,38 & 1302,38 & $1,365 b$ & 98,33 \\
\hline $0,70: 1$ & 958,99 & 1310,30 & $1,370 \mathrm{~b}$ & 98,67 \\
\hline $0,77: 1$ & 971,57 & 1309,85 & $1,354 \mathrm{ab}$ & 98,35 \\
\hline $0,84: 1$ & 970,36 & 1315,75 & $1,358 b$ & 99,44 \\
\hline $0,91: 1$ & 958,33 & 1303,63 & $1,364 b$ & 98,33 \\
\hline \multicolumn{5}{|c|}{ ANOVA - contraste - regressão } \\
\hline ANOVA & ns & ns & $<0,0001$ & ns \\
\hline Contraste & ns & ns & $<0,0001$ & ns \\
\hline Quadrática & - & - & ns & - \\
\hline $\mathrm{CV}(\%)^{1}$ & 3,69 & 3,16 & 1,02 & 1,76 \\
\hline
\end{tabular}

ns: não significativo. 1. Coeficiente de variação. Médias na mesma coluna, seguidas da mesma letra, não diferem estatisticamente entre si ao nível de 5\% de significância.

Entre os tratamentos com diferentes níveis de valina, não foram encontradas diferenças $(\mathrm{P}>0,05)$ entre as médias de nenhuma característica avaliada até os sete dias de idade. Esses resultados diferem de Corzo et al. (2008), que encontraram respostas ótimas para ganho de 
peso, consumo de ração e conversão alimentar com níveis de valina de $1 \%, 0,98 \%$ e $0,99 \%$, respectivamente, o que corresponde a um nível de valina digestível:lisina digestível de 0,77:1, 0,75:1 e 0,76:1, respectivamente, para frangos de corte até 14 dias de idade. Farran e Thomas (1992) encontraram valores ainda inferiores, de $0,90 \%$ de valina total para frangos de até 21 dias.

Segundo Baker et al. (2002), a melhor relação valina:lisina digestível para frangos de corte na fase inicial (oito a 21 dias) seria de 0,775:1 com base no ganho de peso e da eficiência alimentar. Esses valores são similares aos encontrados por Baker (1997) e Mack et al. (1999), que se situam entre 0,77:1 e 0,76:1, respectivamente. Rostagno et al. (2011) propõem recomendações de relação valina:lisina digestível para frango de corte na fase inicial (um-21 dias) de 0,77:1.

Segundo SI et al. (2001), frangos de corte alimentados com níveis marginais de AA tendem a aumentar o consumo de ração para que sejam atendidas tais exigências, porém, no presente estudo, esse fato não foi encontrado até os 21 dias, já que, para o consumo de ração, não houve diferença entre as dietas com níveis diferentes de valina. Talvez o menor nível de valina no presente estudo não tenha sido baixo suficiente para causar tal resposta nos animais.

Os resultados de desempenho encontrados sugerem que uma dieta com níveis adequados de PB gera melhor conversão alimentar até os 21 dias, porém os níveis de valina:lisina digestíveis entre 0,63:1 e 0,91:1 não influenciam no desempenho dos animais.

$\mathrm{Na}$ Tab. 3 se encontram as médias das características de desempenho para frangos de corte de um a 46 dias de idade. Todas as médias das variáveis analisadas no período não diferiram $(\mathrm{P}>0,05)$ entre os tratamentos.

Tabela 3. Médias de ganho de peso (GP), consumo de ração (CR), conversão alimentar (CA), viabilidade criatória (VC) e índice de eficiência produtiva (IEP) de frangos de corte na fase final e em todo o período (um- 46 dias de idade)

\begin{tabular}{|c|c|c|c|c|c|}
\hline \multicolumn{6}{|c|}{$1-46$ dias } \\
\hline Relação (val:lis) & GP (g/ave) & CR (g/ave) & $\mathrm{CA}$ & $\mathrm{VC}(\%)$ & IEP \\
\hline Controle & 3608,61 & 5998,20 & 1,685 & 93,66 & 436,01 \\
\hline $0,63: 1$ & 3541,75 & 5944,62 & 1,696 & 93,88 & 426,63 \\
\hline $0,70: 1$ & 3599,72 & 6005,96 & 1,706 & 92,04 & 422,06 \\
\hline $0,77: 1$ & 3574,81 & 5956,22 & 1,690 & 94,48 & 434,63 \\
\hline $0,84: 1$ & 3566,78 & 5992,23 & 1,690 & 96,66 & 443,67 \\
\hline 0,91:1 & 3569,30 & 5995,38 & 1,695 & 95,00 & 435,55 \\
\hline \multicolumn{6}{|c|}{ ANOVA - contraste - regressão } \\
\hline ANOVA & ns & ns & ns & ns & $\mathrm{ns}$ \\
\hline $\mathrm{CV}(\%)^{1}$ & 1,95 & 1,86 & 1,92 & 4,43 & 5,50 \\
\hline
\end{tabular}

ns: não significativo. ${ }^{1}$ Coeficiente de variação.

Costa et al. (2001), ao testarem níveis de PB na dieta de frangos de corte entre 22 e 42 dias de idade, encontraram efeito linear para conversão alimentar e consumo de ração em que, à medida que o nível de PB aumentava, reduzia-se a conversão alimentar e aumentava-se o consumo de ração, porém sem diferenças para ganho de peso. $\mathrm{Na}$ fase entre 22 e 46 dias (não demonstrado), utilizaram-se, no presente estudo, a média de $18,6 \%$ de PB na dieta controle e a de $17,86 \%$ nas demais dietas, porém essa diferença, juntamente com a maior suplementação de aminoácidos, não gerou diferenças de desempenho entre os tratamentos no período total.
Ferguson et al. (1998) também relataram efeitos negativos no rendimento de frangos de corte de até 21 dias de idade com níveis de proteína de $18,8 \%$. Após esse período, até os 42 dias de idade, não se relataram diferenças $(\mathrm{P}>0,05)$ nas variáveis de desempenho, resultado semelhante ao observado neste estudo.

Resultados similares foram encontrados por Berres et al. (2010) em experimento com frangos de corte que verificou queda de desempenho na primeira metade de vida dos animais. Entretanto, no período total de criação, as aves não apresentaram prejuízos de desempenho devido à 
dieta com teores reduzidos de $\mathrm{PB}$, o que mostra que até os 21 dias a quantidade de nitrogênio adequada ao melhor desempenho dos animais é mais sensível a variações negativas.

Em outro trabalho, Berres et al. (2011), em estudo com frangos de corte em idades de 21 a 42 dias, encontraram melhores níveis de valina:lisina digestíveis para ganho de peso e conversão alimentar de 0,77:1 e 0,76:1, respectivamente. Resultados semelhantes foram encontrados por Corzo et al. (2007), que também trabalharam com frangos de corte na mesma idade e encontraram melhor nível de valina:lisina digestível de 0,78:1. Esses resultados diferem dos encontrados no presente estudo e podem ser explicados pela suplementação de maior número de aminoácidos na dieta deste trabalho, no qual a suplementação de valina digestível na proporção de 0,63:1 de lisina digestível foi suficiente para manter as características de desempenho similares aos demais tratamentos.

Os resultados de rendimento de carcaça em frangos de corte machos abatidos aos 46 dias de idade encontram-se dispostos na Tab. 4.

Tabela 4. Médias de rendimento de carcaça, asa, peito, coxa e sobrecoxa (\%) de frangos machos abatidos com 46 dias de idade

\begin{tabular}{cccccc}
\hline Relação (val:lis) & Carcaça $(\%)$ & Asa $(\%)$ & Peito $(\%)$ & Coxa $(\%)$ & Sobrecoxa $(\%)$ \\
\hline Controle & 72,80 & 10,61 & 33,70 & 13,58 & 18,73 \\
$0,63: 1$ & 72,88 & 10,61 & 33,48 & 13,65 & 18,60 \\
$0,70: 1$ & 73,15 & 10,56 & 34,10 & 13,67 & 18,41 \\
$0,77: 1$ & 73,07 & 10,62 & 33,82 & 13,57 & 18,64 \\
$0,84: 1$ & 73,02 & 10,46 & 33,88 & 13,39 & 18,72 \\
$0,91: 1$ & 73,06 & 10,62 & 32,64 & 13,74 & 18,85 \\
\hline & & ANOVA-contraste - regressão & & ns \\
ANOVA & ns & ns & 0,0464 & ns & ns \\
Contraste & ns & ns & ns & - & - \\
Quadrática & - & - & 0,0087 & - & 2,08 \\
CV $(\%)$ & 0,98 & 2,11 & 2,36 & 2,00 & \\
\hline
\end{tabular}

ns: não significativo. ${ }^{1}$ :Coeficiente de variação

Não se verificaram diferenças significativas $(\mathrm{P}>0,05)$ para as características rendimento de carcaça, rendimento de asa, rendimento de coxa e rendimento de sobrecoxa, corroborando Berres et al. (2011). Esses resultados diferem, entretanto, de Corzo, Dozier e Kidd (2008), que encontraram efeito quadrático para o rendimento de carcaça com nível ótimo de $0,82 \%$ de valina (relação valina:lisina digestivel de 0,72:1). Em outro estudo, Corzo, Moran e Hoehler (2004) avaliaram o efeito de diferentes níveis de valina em frangos de corte de 42 a 56 dias e não observaram diferenças em rendimento de carcaça.

Costa et al. (2001) encontraram efeito linear para rendimento de peito com osso em frangos de corte alimentados com diferentes níveis de $\mathrm{PB}$ dos 22 aos 42 dias de idade, com maior rendimento conforme aumento de PB da dieta.
Tal resultado difere do presente estudo, no qual o nível de redução utilizado não influenciou o rendimento de peito. Em concordância com este, Kidd et al. (2006) relatam que níveis baixos de PB suplementados com aminoácidos não afetam o rendimento de peito dos animais.

$\mathrm{O}$ contraste entre as médias de rendimento de peito (RP), entre o tratamento controle e os demais tratamentos, não diferiu entre si $(\mathrm{P}>0,05)$. Porém, para a análise de regressão, observou-se efeito quadrático $(\mathrm{P}=0,0087)$ para rendimento de peito $\left(\mathrm{y}=6,2074+74,149 \mathrm{x}-49,271 \mathrm{x}^{2}\left(\mathrm{r}^{2}=\right.\right.$ $0,90)$ entre os tratamentos com níveis de valina, com valor ótimo de valina:lisina digestível de 0,75:1, valor superior ao encontrado por Corzo et al. (2007) e Corzo, Dozier e Kidd (2008), que obtiveram valores ótimos de 0,72:1 e 0,70:1, respectivamente, para rendimento de peito. 


\section{CONCLUSÕES}

As diferentes relações valina:lisina digestíveis não influenciaram o desempenho dos animais em nenhuma fase de criação, porém afetaram o rendimento de peito, com relação ótima de valina:lisina digestível de 0,75:1. Portanto, o nível de 0,63:1 de relação valina:lisina digestível foi suficiente para manter o desempenho dos animais. A redução proteica associada com a suplementação de aminoácidos industriais afeta o desempenho dos animais em sua primeira metade de vida (três semanas); já após esse período, tal prejuízo em desempenho não é visualizado. Essa redução proteica não influenciou o rendimento de carcaça e cortes.

\section{REFERÊNCIAS}

BAKER, D.H. Ideal amino acid profiles for swine and poultry and their applications in feed formulation. St Louis: Biokyowa Technol. Rev., v.9, p.1-24, 1997.

BAKER, D.H.; BATAL, A.B.; PARR, T.M. et al. Ideal ratio (relative to lysine) of tryptophan, threonine, isoleucine, and valine for chicks during the second and third weeks posthatch. Poultry Sci., v.81, p.485-494, 2002.

BERRES, J.; VIEIRA, S.L.; DOZIER III, W.A. et al. Broiler responses to reduced-protein diets supplemented with valine, isoleucine, glycine, and glutamic acid. J. Appl. Poult. Res., v.19, p 69-79, 2010.

BERRES, J.; VIEIRA, S.L.; FAVERO, A. et al. Digestible valine requirements in high protein diets for broilers from twenty-one to forty-two days of age. Anim. Feed Sci. Technol., v.165, p.120-124, 2011.

CANCHERINI, L.C.; JUNQUEIRA, O.M.; OLIVEIRA, M.C. et al. Utilização de subprodutos de origem animal em dietas formuladas com base em proteína bruta e proteína ideal para frangos de corte de 22 a 42 dias de idade. Rev. Bras. Zootec., v.4, p.5355402005.

CORZO, A.; KIDD, M.T.; DOZIER III, W.A.; VIEIRA, S.L. Marginality and needs of dietary valine for broilers fed certain all-vegetable diet $J$. Appl. Poult. Res, v.16, p. 546-554, 2007.
CORZO, A.; DOZIER III, W.A.; KIDD, M.T. et al. Valine nutrient recommendations for Ross $\mathrm{x}$ Ross 308 broilers. Poultry Sci., v.87, p.335-338, 2008.

CORZO, A.; LOAR II, R.E.; KIDD, M.T. et al. Limitations of dietary isoleucine and valine in blroiler chick diets. Poultry Sci., v.88, p.19341938, 2009.

CORZO, A.; MORAN Jr., E.T.; HOEHLER, D. Valine needs of male broilers from 42 to 56 days of age. Poultry Sci., v.83, p.946-951, 2004.

COSTA, F.G.P.; ROSTAGNO, H.S.; ALBINO, L.F.T. et al. Níveis dietéticos de proteína bruta para frangos de corte de 1 a 21 e 22 a 42 dias de idade. Rev. Bras. Zootec., v.30, p.1498-1505, 2001.

FARRAN, M.T.; THOMAS, O.P. Valine deficiency. 1: the effect of feeding a ValineDeficient diet during the starter period on performance and feather structure of male broiler chicks. Poultry Sci., v.71, p.1879-1884, 1992.

FERGUSON, N. S.; GATES R.S.; TABARA J.L. et al. The effect of dietary protein ans phosphorus on ammonia concentration and litter composition in broilers. Poultry Sci., v.77, p.1085-1093, 1998.

HISANO, H.; PORTZ, L. Redução de custos de rações para tilápia: a importância da proteína. Rev. Bahia Agríc., v.8, p.42-45, 2007.

KIDD, M.T., KERR, B.J., FIRMAN, J.D; BOLING, D. Growth and carcass characteristics of broiler fed low-protein, threonine supplemented diets. J. Appl. Poul. Res., v.5, p.180-190, 1996.

MACK, S.; BERCOVICI, D.; DE GROOTE, G. et al. Ideal amino acid profile and dietary lysine specification for broiler chickens of 20 to 40 days of age. Br. Poult. Sci., v.40, p.257-265, 1999.

MENDES, A.A., MOREIRA, J.; OLIVEIRA, E.G. et al. Efeitos da energia da dieta sobre desempenho, rendimento de carcaça e gordura abdominal de frangos de corte. Rev. Bras. Zootec., v.33, p.2300-2307, 2004.

OFFICIAL methods of analysis. Washington, DC.: Association of Official Analytical Chemists, 1996. 
ROSTAGNO, H.S.; ALBINO, L.F.T.; DONZELE, J.L. et al. Tabelas brasileiras para aves e suínos: composição de alimentos $\mathrm{e}$ exigências nutricionais 3.ed. Viçosa: Editora UFV, 2011.

ROSTAGNO, H.S.; VARGAS JR, J.G.; ALBINO, L.F.T. et al. Níveis de proteína e de aminoácidos em dietas de pinto de corte. In: CONFERÊNCIA APINCO DE CIENCIA E TECNOLOGIA AVICOLAS, 2002, Campinas. Anais... Campinas: Associação Brasileira de Produtores de Pinto de Corte, 2002. p.49.
STAT user's guide. 4.ed. Cary, NC: SAS Institute Inc., 2002. v.9.1.

SI, J.; FRITTS, C.A.; BURNHAM, D.J.; WALDROUP, P.W. Relationship of dietary lysine level to the concentration of all essential amino acids in broiler diets. Poultry Sci., v.80, p.1472-1479, 2001.

SILVA, Y.L.; RODRIGUES, P.B.; FREITAS, R.T.F. et al. Redução de proteína e fósforo em rações com fitase para frangos de corte no período de 1 a 21 dias de idade: desempenho e teores de minerais na cama. Rev. Bras. Zootec., v.35, p.840-848, 2006. 